\title{
Doğuştan çarpık ayak: sağaltıma tarihsel bir bakış
}

\author{
Congenital clubfoot: a historical perspective of treatment
}

\author{
Nusret Köse ${ }^{1}$, Bartu Sarıözen² \\ 1'Osmangazi Üniversitesi Tıp Fakültesi, Ortopedi ve Travmatoloji Anabilim Dalı, Eskişehir \\ Uludağ Üniversitesi Tıp Fakültesi, Ortopedi ve Travmatoloji Anabilim Dalı, Bursa
}

\begin{abstract}
Günümüzün en önemli doğuştan ortopedik sorunları içinde ilk sıralarda yer alan doğuştan çarpık ayak (DÇA), aslında tarih boyunca insanların dikkatini devamlı çeken bir hastalık olmuştur. Seri alçılama ile yapılan konservatif tedavinin başarısızlığı, konu ile uğraşan ortopedistlerin yeni cerrahi yöntemler geliştirmelerine ve bunları ön plana çıkarmalarına neden oldu. Ancak, ideal cerrahi yöntem de bulunamadı. Sonraki dönemde, Dr. Ignacio V. Ponseti, kendi yöntemini tanıttı; onun kibar ve cerrahi olmayan düzeltme yöntemi, giderek, binlerce çocuğun yürümesine yardımcı olan, günümüzün standart birincil tedavisi konumuna yükseldi.
\end{abstract}

Congenital clubfoot is one of the most important congenital anomalies in orthopedics today and it has been a disease that attracts people's attention constantly throughout history. Because of failure of conservative treatment with serial casting, orthopedic surgeons concentrated on the development of new surgical techniques. However, the ideal surgical method could not be found. Then, Ponseti gradually introduced his method. Dr. Ignacio V. Ponseti, whose gentle, nonsurgical method of correcting clubfoot has become the global standard for treatment, helping thousands of children to walk.
G ünümüzün en önemli doğuştan ortopedik sorunları içinde ilk sıralarda yer alan doğuştan çarpık ayak (DÇA), aslında tarih boyunca insanların dikkatini devamlı çeken bir hastalık oldu. Bunun herhalde en önemli nedenleri, diğer doğumsal ortopedik sorunlarla kıyaslandığında göreceli sıklığı, düzeltilmeye gösterdiği direnç ve doğumla birlikte hemen göze batmaya başlayarak ömür boyu sakatlığa neden olmasıdır. Eski Mısır kalıntılarında DÇA resmedilmiştir ve o günden bu yana, edebiyat ve resim gibi tıp dışı alanlarda da işlenen bir konu olmuştur. Örneğin; Gustave Flaubert, Madame Bovary romanında DÇA'lı bir karaktere yer vererek bu hastalığı işlemiş, hatta karakterinin tedavisini sonunda ampütasyonla bitirmiştir.

Yazılı olarak günümüze ulaşan ilk tıbbi nitelikteki DÇA bilgileri, elbette Hipokrat'a aittir. İlginç olan, bugün güncel tedavide geçerli olan, seri manipülasyon uygulamak, zorlayıcı olmamak, tedaviye olabildiğince erken başlamak, aşırı düzeltme yapmak ve düzeldikten sonra ayağın pozisyonunu devam ettirmek gibi önemli başlıkları, Hipokrat yaklaşık 2400 yıl önce açıklamıştır.
Hipokrat'tan sonra yüzyıllar boyunca belirgin hiçbir gelişme göstermeyen DÇA tedavisi, 19. yüzyıla gelindiğinde ise aşırı zorlu manipülasyonlar ve gerdirmeler yapan cihazlarla ve ayakkabılarla tedavi edilmeye çalışılmıştır. Bu dönemlerde aşil tendonuna yönelik gevşetme girişimleri denenmişse de, çoğu kez sepsise kadar giden enfeksiyonlar, deneyenlerin cesaretini kırmıştır. Spastik diplejiyi ilk tanımlayan kişi olan İngiliz cerrah W. J. Little, aynı zamanda batı dünyasında ekinovarus deformitesinde perkütan aşil tenotomisini ilk tanıtanlardan birisi olmuştur. Little, çocukluğunda poliomiyelit geçirmiş ve buna bağlı olarak, ayaklarındaki ciddi pes ekinovarus deformitesi nedeniyle, kendisi de perkütan aşil tenotomisi olmuştu.

Zaman içinde, sterilite, cerrahi teknikler, alçılama gibi alanlarda ciddi gelişmeler olmasına karşın, DÇA tedavisinde bu gelişmelere paralel bir başarı sağlanamadı. Bunun belki de en önemli nedeni, alçılamanın patolojiyi tam bilmeden yapılıyor olması, bu nedenle çocukların önemli bir kısmında iyatrojenik deformiteler gelişmesi ve sonucun nadiren yüz güldürücü olmasıydı. Hiram Kite, 1939 yılında DÇA tedavisi üzerine kaleme

- İletişim adresi: Prof. Dr. Nusret Köse, Eskişehir Osmangazi Üniversitesi Tıp Fakültesi, Ortopedi ve Travmatoloji Anabilim Dalı, Eskişehir Tel: 0222 - 2392979 e-posta: drnkose@gmail.com

- Geliș tarihi: 25 Mayıs 2015 Kabul tarihi: 25 Mayıs 2015 


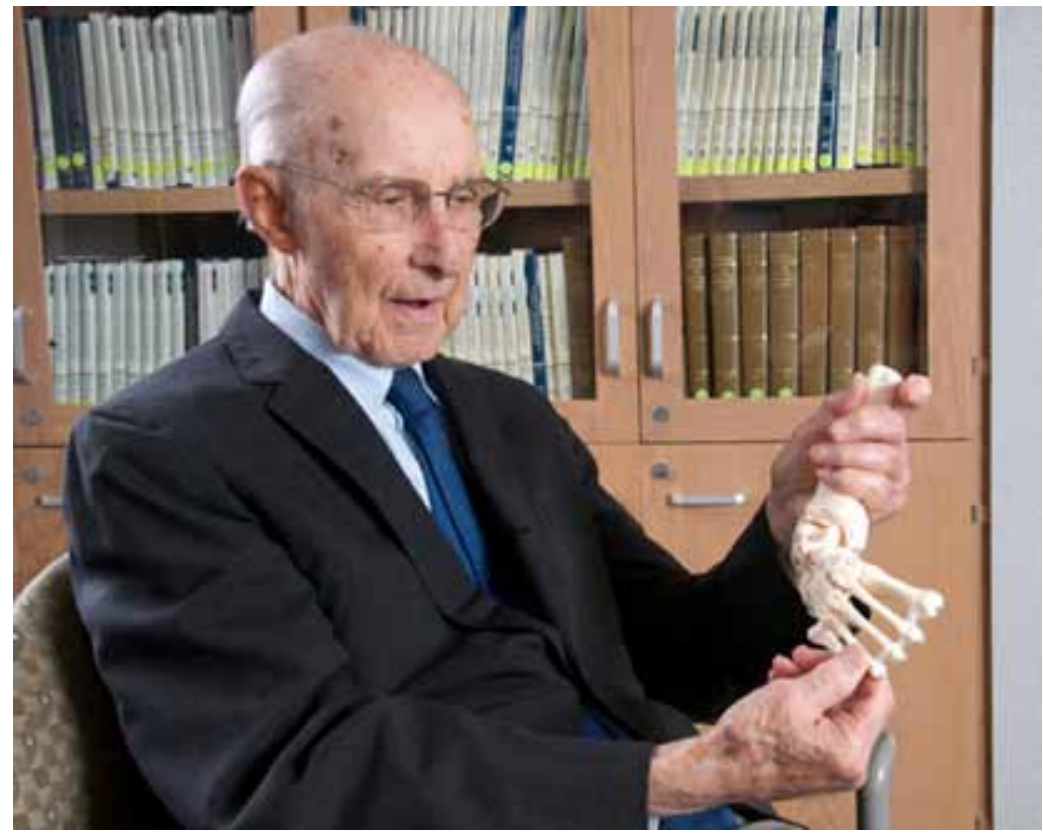

Şekil 1. Dr. Ignacio V. Ponseti (nytimes com).

aldığı kitabını yayımladı. Yirminci yüzyılın önemli bir bölümünde, DÇA'ın konservatif tedavisi Kite prensiplerine göre uygulandı. Kite'ın alçılama yönteminde, deformitenin parçaları birlikte değil, tek tek ve belirli bir sıra dahilinde düzeltiliyordu. Alçı yapılırken ayak abduksiyona zorlanmaktaydı; bu anda ayak dış yüzünde kalkaneoküboid ekleme basılarak, karşı kuvvet uygulanıyordu. Dolayısıyla, bu manevra aslında kalkaneusun hareketini engellediğinden, topuk varusunun düzelmesi çok zordu ve deformitenin bu komponentini düzeltmek için yapılan alçı sayısı çoktu.

Seri alçılama ile yapılan konservatif tedavinin bu başarısızlığı, konu ile uğraşan ortopedistlerin giderek yeni yeni cerrahi yöntemler geliştirmelerine ve bunları ön plana çıkarmalarına neden oldu. Özellikle 20. yüzyılın ikinci yarısı, bu cerrahi tekniklerin bir anlamda moda haline geldiği ve yaygınlaştığı bir dönem oldu. Ancak ideal cerrahi yöntem de bulunamadı; çünkü, cerrahinin zamanlaması, sınırları veya tekniği konusunda ortak kanılar oluşmamıştı. Bunun en önemli nedeni ise, cerrahi yöntem hangisi olursa olsun, belirli bir oranın üzerinde başarılı sonuç sağlayan, düzelme miktarı kontrol edilebilen, eklem hareketlerinin ve kas güçlerinin korunmasına olanak sağlayan ve tekrar cerrahi tedavi uygulanmasını gereksiz kılan bir tekniğin geliştirilememiş olmasıydı. İşte, DÇA'nın ideal tedavisi konusunda belirsizliğin hakim olduğu bu dönemde, Ignacio V. Ponseti (Şekil 1) kendi yöntemini tanıttı ve giderek bu yöntem yaygınlaşarak günümüzün standart birincil tedavisi konumuna yükseldi. ${ }^{[1-3]}$

Ponseti alçılama tekniği; ayaktaki patolojiyi doğrudan düzeltmek yerine, deformitenin anatomisini doğru ve ayrıntılı anlamaya ve bunu düzeltmeye çalışan, basit, öğrenme süresi kısa, çeşitli koşullarda ve mekanlarda uygulanabilen, önemli bir malzeme ve kalabalık bir ekip gerektirmeyen, bu nedenlerle de Batı dünyasında olduğu kadar gelişmekte olan ve geri kalmış ülkelerde de yaygınlaşabilen ve başarı ile uygulanan bir yöntemdir. Ponseti, yöntemi ile ilgili çok sayıda çalışma yayımlanmıştır. Farklı merkezlerde başarı, nüks, aşil tendon gevşetme ve ikincil girişim oranlarının değişen sıklıklarda bildirilmesine, alçılama sonrası cihaza uyum ve kullanma düzeni ile ilgili halen soru işaretleri bulunmasına karşın, bu yöntem giderek daha da yaygınlaşmakta ve ideal uygulama şartlarının belirlenmesi için çalışmalar devam etmektedir.

\section{KAYNAKLAR}

1. Ponseti IV, Morcuende JA. Current management of idiopathic clubfoot questionnaire: a multicenter study. J Pediatr Orthop 2004;24(4):448.

2. Ponseti IV, Smoley EN. The classic: congenital club foot: the results of treatment. 1963. Clin Orthop Relat Res 2009;467(5):1133-45. CrossRef

3. Martin D. Ignacio Ponseti, Hero to Many With Clubfoot, Dies at 95. The New York Times, October 24, 2009. Erişim: http:// www.nytimes.com/2009/10/24/health/research/24ponseti. html?_r=1\& 